\title{
EDUCAÇÃO SUPERIOR E QUALIFICAÇÃO PARA O DESENVOLVIMENTO ECONÔMICO NACIONAL
}

\section{HIGHER EDUCATION AND QUALIFICATION FOR NATIONAL ECONOMIC DEVELOPMENT}

\author{
Herbert Schutzer ${ }^{1}$ \\ Solange Camilo Asen Campos ${ }^{2}$
}

\section{RESUMO}

A relação entre ensino superior e a economia nacional contribui para o desenvolvimento econômico e possibilita alavancar o crescimento socioeconômico de toda a população do país, segundo muitos autores. A partir dessa premissa, procurou-se observar como o ensino superior no Brasil se estabeleceu, que características possui atualmente e contribui ou pode contribuir para o desenvolvimento. Neste trabalho buscou-se mostrar as transformações por que passou o ensino superior na nossa história para que se perceba uma mudança de orientação do modelo de ensino decorrente do amadurecimento do país com uma consequente política regulatória para amparar as mudanças. $\mathrm{O}$ maior acesso ao ensino superior em todo o território nacional em tese produz maiores influências no desenvolvimento econômico. E isso é decorrente de uma maior produção científica nas IES, de natureza qualitativa, melhorando o capital humano formado pelo ensino superior e também sua participação mais ativa na esfera econômica do país. Embora ainda não suficiente para alavancar mais efetivamente o desenvolvimento como ocorreu em outros países.

Palavras-chave: Desenvolvimento. Ensino superior. Produtividade. Qualitativo.

\begin{abstract}
The relationship between higher education and the national economy contributes to economic development, and provides leverage to the socio-economic growth of the country's entire population, according to many authors. From this assumption, we tried to see how higher education in Brazil has been established, which features it currently has and whether or not it contributes to development. This work aimed to show the changes that higher education went through in our history in order to notice a change of direction of the teaching model, resulting from the country's maturity with a following regulatory policy to support the changes. Greater access to higher education throughout the national territory in theory produces major influences on economic development. And this is due to increased quality scientific production in IES, improving human capital trained by higher education and also their more active participation in the country's economic arena. Although still not enough to leverage more effectively the development as in other countries.
\end{abstract}

Keywords: Development. Higher education. Productivity. Qualitative.

\footnotetext{
${ }^{1}$ Estácio Radial. Departamento de licenciaturas - Av. Sen. Souza Naves, 1715, Curitiba, PR CEP: 80050-040. E-mail: hschutzer@globomail.com

${ }^{2}$ Estácio Radial. Departamento de licenciaturas - Av. Sen. Souza Naves, 1715, Curitiba, PR CEP: 80050-040. E-mail: asen.solange@gmail.com
} 


\section{Introdução}

A interação entre o ensino superior e o setor produtivo no Brasil é uma das condições necessárias para o desenvolvimento econômico. Nessa perspectiva, procurouse observar como esse nível educacional pode contribuir para o crescimento do país.

A influência do ensino superior na economia nacional teve uma trajetória descompassada, enquanto a economia crescia, o ensino superior apresentava o distanciamento que historicamente mantinha da economia. $\mathrm{O}$ ensino superior desde a sua implantação no Brasil teve uma orientação humanista, mais vinculada a uma produção literária filosófica do que técnica. Dessa forma, só com o amadurecimento do pensamento nacional é que o ensino superior começou a enveredar na área de tecnologia sem que pudesse contribuir efetivamente com o desenvolvimento.

Tendo em vista ser uma questão ampla e complexa, procurou-se fazer um recorte na esfera estrutural e da produtividade do ensino superior para sustentar a argumentação que reforça a necessidade da interação universidade e mercado.

O problema derivado dos pressupostos apresentados é buscar entender como o ensino superior contribui e está contribuindo com o desenvolvimento econômico do país. Quais as características desse nível de ensino e como ele pode participar do projeto de desenvolvimento que o país pretende alcançar.

Aborda-se o tema a partir das relações entre educação e desenvolvimento, fazendo-se a seguir um breve aporte histórico da educação superior no Brasil. Destacam-se também os modelos de universidade e as tendências desse nível de ensino nas últimas décadas; na sequência, mostra-se a importância do ensino superior para o desenvolvimento nacional. E, finalmente, apresentam-se os recortes da estrutura universitária e sua produção científica nos últimos anos, destacando a quantidade e a qualidade da produção científica que pode sustentar o desenvolvimento econômico do país.

A pesquisa desenvolvida foi a descritiva, com o objetivo de descrever as características do fenômeno ensino superior-desenvolvimento, buscando estabelecer relações entre variáveis encontradas. Uma das características mais significativas neste trabalho foi a utilização de técnicas padronizadas de coleta de dados. 


\section{A Educação para o desenvolvimento econômico e social no mundo}

Um dos aspectos relevantes da sociedade brasileira é o papel da educação superior no sentido das funções que ela exerceu nos últimos 200 anos. As relações entre a educação e a economia é algo que preocupa e preocupou por igual todos os países em qualquer etapa do seu desenvolvimento. As sociedades industriais mais avançadas no momento atual são aquelas que tomaram consciência da importância de levar em consideração as conexões entre a educação, o estado da economia e a estrutura social. A intensidade da percepção do problema se apresentou dentro das condições históricas que o progresso impulsionou, sendo fato que o homem das modernas sociedades avançadas não renunciou em intervir no seu futuro, o que levou a destacar a fundamental importância da educação para constituir a energia necessária ao desenvolvimento (ECHEVARRÍA, 1974).

A tomada de consciência que se observou nas sociedades industriais na segunda metade do século XIX deve-se a alguns matizes que aqui somente apresentamos, sem precisar todas as razões manifestas nelas. Pode-se afirmar que nelas difundiu-se um generalizado senso de igualitarismo, que consolidou o regime democrático, com a consequente repercussão da ampliação da necessidade de escolarização. Um segundo ponto relevante, a dinâmica social por essas sociedades em expansão, impulsionou a capacidade produtiva. A tecnificação geral do modo de vida dessas sociedades necessitava do aporte científico e uma especialização do sistema de ocupações, exigindo maior preparação técnica do campo educacional (ECHEVARRÍA, 1974).

As preocupações dos países que estão em desenvolvimento também tomaram consciência da relação fundamental entre educação, economia e estrutura social, no entanto, essas preocupações atingem intensidades diferentes, como é natural, devido às características peculiares de cada um. Nesse sentido, o Brasil possui particularidades que se manifestam de forma diversa e segundo o grau evolutivo que a sociedade se encontra. As tradições educacionais seculares é um obstáculo aos acontecimentos que se manifestaram em países mais adiantados de outros continentes, cujos procedimentos educacionais são mais refinados e podem exportar seus modelos para os países em desenvolvimento. A partir desse pressuposto, os países em desenvolvimento podem 
adotar um modelo já testado nos países centrais e impulsionar seu desenvolvimento mais rapidamente do que partindo do zero (ECHEVARRÍA, 1974).

Analisar o problema da educação como fator de desenvolvimento implica muitos desdobramentos e ramificações, desse modo, a análise será feita em linhas gerais. Assim, pode-se observar a educação como investimento, os esforços para a qualificação por meio da educação são um dos importantes meios para a ampliação da produtividade econômica, que aumentam as taxas de lucro do capital. O campo educacional, a teoria da capital humano e sua concepção tecnicista disseminaram a ideia do desenvolvimento econômico e do indivíduo ao se educar. (SCHULTZ, 1973). ${ }^{3}$ Dessa premissa, o capital humano saiu do âmbito individual e ganhou conotação de inserção social, do emprego e do desempenho profissional e fez da educação um "valor econômico". Legitimando a ideia de que a educação é um investimento determinado pelos critérios capitalistas, sendo indispensável para o desenvolvimento. Outra percepção é a de que as conexões entre educação e desenvolvimento econômico se aplicam na demanda por quadros profissionais, em que se torna impossível ampliar a atividade econômica mais complexa sem um quadro profissional de especialistas com o mais alto grau de formação intelectual. Isso implica uma educação como instrumento de oferta acertada com as projeções dos sistemas ocupacionais (ECHEVARRÍA, 1974).

Uma terceira concepção, mais moderna, da educação como fator decisivo do desenvolvimento econômico tem sido a ideia do planejamento. A educação deve estar em todo plano de desenvolvimento, e a planificação deve ser introduzida com pleno rigor no sistema educacional. Constata-se a necessidade de integrar o planejamento educacional com a planificação geral da economia, sendo um desafio que as condições históricas das sociedades em desenvolvimento impõem para a educação (ECHEVARRÍA, 1974).

\section{A formação do Ensino Superior no Brasil: breve história de seu início}

No Brasil, o ensino superior começou a se desenvolver após a chegada da família real portuguesa ao Rio de Janeiro, em 1808. Foi o momento em que a corte

\footnotetext{
${ }^{3}$ A teoria do capital humano ganhou espaço no Brasil a partir do fim da década de 1970. Uma boa parte da literatura existente sobre o capital humano atribui à educação e ao mercado de trabalho o papel de principais determinantes da formação da renda do indivíduo e, consequentemente, determinantes do desenvolvimento socioeconômico de um país. Além disso, para os defensores da teoria de Capital Humano no Brasil, a educação teria um papel fundamental na diminuição das desigualdades socioeconômicas, geradas pela exclusão de grande parte dos indivíduos do sistema econômico vigente.
} 
portuguesa passou a residir na colônia, fugindo do avanço das forças de Napoleão Bonaparte, que prometia invadir e anexar Portugal ao seu império. A vinda da Família Real causou um grande impacto sociocultural na colônia.

Naquela época, mais da metade dos 3,5 milhões de habitantes do país eram escravos e, para atender às novas exigências e reivindicações da população, foram criadas instituições de caráter técnico e científico, tais como as escolas de Cirurgia da Bahia e de Anatomia e Cirurgia no Rio de Janeiro, as academias dos Guardas-Marinhas e Real Militar, o Real Horto e o Museu Real. Todas elas foram fundadas na primeira metade do século XIX, com o principal objetivo de formar quadros para o Estado e cumprir finalidades práticas e imediatas de qualificar profissionais destinados à saúde, à defesa e à segurança do território e ao conhecimento das riquezas naturais brasileiras, sendo que alguns de seus integrantes e associados estimularam a criação de um número crescente de novas instituições capazes de impulsionar o desenvolvimento técnico, científico e tecnológico em terras brasileiras (NAGAMINI, 2004).

Entretanto, foi somente após a Proclamação da Independência, em 1822, e da República, em 1889, que se formaram as condições políticas e sociais para a criação das primeiras universidades oficiais do Brasil: a Universidade do Rio de Janeiro, em 7 de setembro de 1920, e a Universidade de São Paulo (USP), fundada em 1934 - a primeira seguindo o modelo de universidade francês, e a segunda, o modelo alemão. Houve tentativas anteriores que não se concretizaram ou mesmo universidades privadas que foram formadas mas não se estabeleceram, sendo fechadas em pouco tempo, como a Universidade de Manaus (1909), de São Paulo (1911) e do Paraná (1912). Um dos motivos desses fracassos, aponta a professora da Faculdade de Educação da UFRJ, Maria de Lourdes Albuquerque Fávero (2006), em seu texto, era o fato de que a elite da época preferia enviar seus filhos para universidades europeias, como a Universidade de Coimbra.

\subsection{Modelos de universidades com influências no Brasil}

A universidade de modelo francês era uma instituição de caráter fragmentado e profissionalizante, formada pela consolidação de escolas isoladas, com dissociação entre ensino e pesquisa e que tivesse como papel central a formação de mão de obra especializada, para suprir as necessidades práticas da sociedade na qual estava inserida. 
O modelo alemão tinha como preocupação introduzir a pesquisa científica como elemento-chave da universidade. Conforme apresentado no texto "A Formação Universitária no Brasil: concepções e influências", de Maria de Fátima Paula, coordenadora do Núcleo de Estudos e Pesquisas em Educação Superior da Universidade Federal Fluminense (UFF), esse modelo colocava a Faculdade de Filosofia, Ciências e Letras no "coração da instituição", funcionando como centro integrador e catalisador da ideia de uma universidade responsável pela produção de ciência livre e desinteressada, de cunho humanista e não pragmático (CEPAL, 1962).

Esses dois modelos de universidade, assim como o modelo americano (de Whitehead, segundo o qual deve haver uma interação entre ensino e pesquisa com o objetivo de produzir conhecimento aplicado, útil para o progresso da sociedade), serviram de base para a concepção e a estrutura do ensino superior no Brasil ao longo de sua história (CEPAL, 1962).

O formato assumido pelo ensino superior no Brasil, segundo Carneiro (1998), de conteúdo generalizante e humanístico, terminou por repercutir no próprio ensino secundário. Com um caráter propedêutico, voltado para os vestibulares de acesso às universidades, não se avançou no ensino técnico voltado para atender as demandas do desenvolvimento econômico.

O rigor, o intelectualismo, a desvinculação da realidade e do mundo do trabalho que caracterizaram o ensino superior dessa época, além de herança do passado colonial, eram também traços marcantes de uma sociedade elitista e excludente. Nesse sentido, o modelo de ensino superior adotado também corroborava com a manutenção desse tipo de sociedade e do pensamento positivista dominante nesse contexto. A emergência de uma nova concepção de universidade numa nítida reação ao positivismo dominante. Isso se reflete na proposta de criação de universidades com consequente desenvolvimento de atividades de pesquisa (MELO; SANTOS; ANDRADE, 2009).

\subsection{Tendências da educação superior}

Atualmente o ensino superior no mundo e no Brasil expressa novas tendências, como a extinção de departamentos e o estímulo à interdisciplinaridade e à formação humanística aliada à técnica, com um ciclo básico de formação. Peter Schulz, diretor da FCA/Unicamp, afirmou a esse respeito: “A não existência de departamentos fomenta e 
promove a interdisciplinaridade, propiciando uma nova forma de ensino - por projetos, em equipes e baseado em problemas reais, que são interdisciplinares".

A USP e a Universidade de Brasília (UnB), por sua vez, aderiram aos Massive Open Online Courses (MOOCS ou "cursos online abertos ao grande público"), uma das seis tecnologias que, segundo o relatório NMC Horizon 2013 Higher Education Edition, devem provocar profundas mudanças no ensino superior nos próximos cinco anos, permitindo que um número cada vez maior de pessoas tenha acesso a esse nível de ensino.

É possível perceber que no Brasil a percepção da importância do ensino superior vem se alterando, o papel da educação no desenvolvimento econômico é mais evidente em relação à formação de mão de obra profissional e técnica e também a sua inversão tecnológica, a difusão de inovações, a aptidão empresarial, os padrões de consumo, a adaptabilidade às mudanças econômicas e a integração de distintos setores nas tarefas do desenvolvimento.

É antiga a visão de que a necessidade de estudos para determinar a alocação ótima de recursos na educação seja incluída nos planos de desenvolvimento. Para que os riscos de erros diminuam e a produtividade aumente, a partir da melhoria da educação transmite ou modifica valores de uma sociedade encaminhando para o desenvolvimento econômico (CEPAL, 1962).

De outro lado, a tendência das políticas em curso, que criaram os cursos chamados tecnológicos com dois anos de duração, serviu para aumentar a separação entre os processos de ensino e a pesquisa no país (SANTOS; FREITAS, 2010). Inúmeras IES foram criadas esvaziadas de conteúdo, com uma visão alargada da profissão no econômico-social, nas bases filosóficas e políticas do campo profissional, além da incipiente pesquisa realizada, e são as que mais crescem em todo o país, as instituições privadas. "Esse pragmatismo voltado às necessidades do mercado acaba por dificultar uma formação fundamentada teórica e criticamente, capaz de levar o profissional a analisar a realidade social propor alternativas para sua transformação" (FRANCO, 2001). 


\section{A Educação Superior impulsiona o país para o desenvolvimento}

O desenvolvimento nacional, segundo Pereira (2006), constitui-se em um processo histórico que é determinado por dois fatores, a existência ou não de uma estratégia, da qualidade dessa estratégia e da coesão da nação e do acerto das instituições criadas e das políticas adotadas. Uma economia apresenta desenvolvimento quando seu governo, seus empresários, técnicos e trabalhadores estão trabalhando afinados a uma estratégia planejada.

A perspectiva adotada de desenvolvimento pressupõe $\mathrm{o}$ aumento de produtividade dos trabalhadores de serviços de baixo valor agregado para a de bens e serviços de alto valor adicionado por trabalhador, caracterizado pela qualificação da mão de obra. Tal viés de desenvolvimento parte da ideia da necessidade de se defender fortemente a propriedade intelectual, que fornece bens e serviços qualificados e que exige o trabalho com elevado nível de educação, ou seja, com conhecimento técnico, administrativo e de comunicação alcançados via educação superior (PEREIRA, 2006).

Finalmente se distingue que o desenvolvimento não apenas como uma acumulação de capital, mas um processo que vem acompanhado de progresso técnico, que engloba as esferas estratégicas da técnica, do administrativo e da comunicação, permitindo distinguir dois tipos de capital, o físico e o humano. Assim, é cada vez mais importante o papel do capital humano para o progresso técnico e surge a exigência de se manter uma proporcionalidade entre o capital físico e o capital humano. Isso indica que o planejamento deve conter em seu escopo as relações entre mercado e educação (PEREIRA, 2006).

A estratégia nacional de desenvolvimento tem a liderança do governo, que age integrado com os agentes econômicos e instituições de diversas naturezas, entre elas as educacionais, definindo políticas econômicas que promovam investimentos e aumento da produtividade.

No Brasil, o desenvolvimento econômico esteve vinculado a uma política de substituição de importações (ARBIX, 2006). Modernamente, busca-se abandonar essa perspectiva visando um modelo diferente que permite articular o conjunto do sistema produtivo com o acúmulo de conhecimento que se desenvolve há décadas. Dessa forma, 
a inovação é a chave da grande transformação que é preciso operar no sistema produtivo brasileiro, e para a qual a participação das IES é imprescindível.

Podemos observar no Gráfico 1 que o Brasil apresentou um crescimento do PIB sistemático na última década. Esse panorama, segundo a perspectiva de Schumpeter (1961), pode ser definido sem entrar no mérito da questão, a partir da distinção entre desenvolvimento e crescimento, em que o desenvolvimento envolve transformações sociais e políticas e o crescimento, um mero aumento da renda per capita.

Gráfico 1 - Crescimento do PIB de países em desenvolvimento

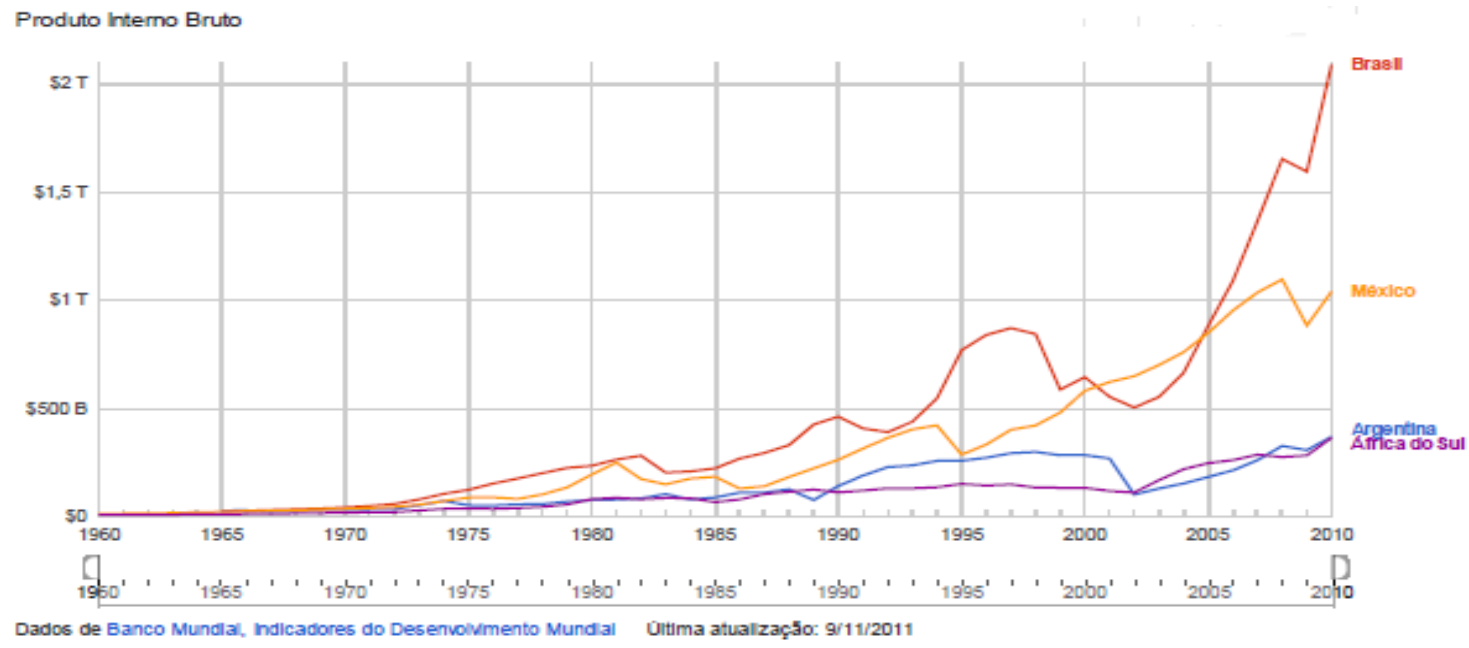

Fonte: elaborado pelos autores (2014).

A ascensão do PIB brasileiro mostra que sua economia apresentou uma maior dinâmica que outros países do mesmo nível, e é conveniente destacar a participação de uma nova política industrial, tecnológica e de comércio exterior (PITEC), lançada em 2004, que contribuiu para alcançar esse patamar. No entanto, quando observamos (Gráfico 2) a participação das exportações, os indicadores apontam que o Brasil não apresentou um aumento significativo da participação do indicador com relação ao seu PIB. 
Gráfico 2 - Participação das exportações no PIB

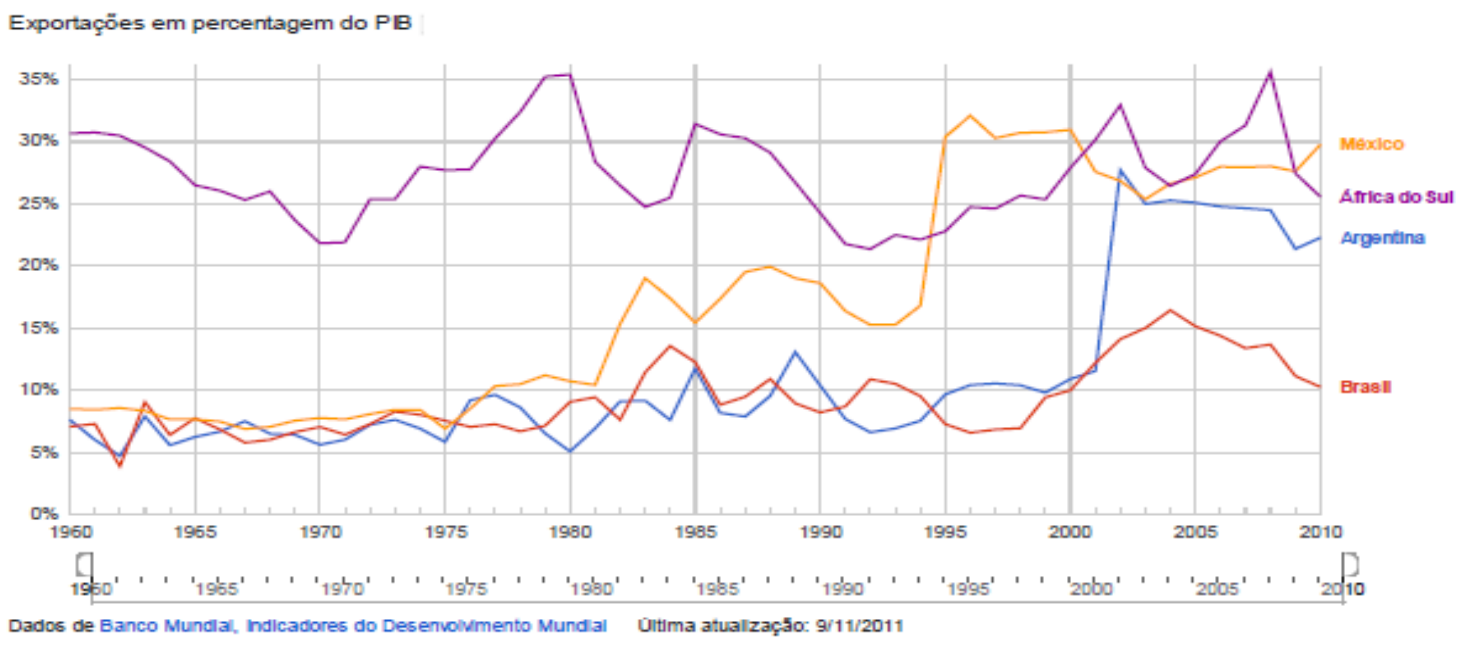

Fonte: elaborado pelos autores (2014).

O que se pode denotar pela variação dos indicadores do Brasil e em relação aos outros países em desenvolvimento é a falta de maior qualificação dos produtos exportados, com predomínio da exportação de produtos de baixa tecnologia e/ou valor agregado. Caracterizando uma pequena participação das mercadorias de alta tecnologia, decorrente de um subaproveitamento do capital humano disponível no país, denotando um aprendizado tecnológico passivo, ou não aproveitamento do conhecimento formado pelas IES.

\subsection{A oferta do capital humano pela educação superior}

O ensino superior nas últimas décadas apresentou um aumento do número de instituições e de matrículas, que mostra uma preocupação das políticas de desenvolvimento no sentido de melhorar a qualificação da mão de obra brasileira. E com a implantação de uma nova política industrial, a meta é sempre buscar maior produtividade e participação na competição global de comércio. Para isso o ensino superior deve estar em sintonia com a economia cada vez mais competitiva.

A região mais dinâmica do país, onde se concentra a mais qualificada produção, possui 48,77\% das IES, por ser a região que promove um desenvolvimento high-tech baseado no conhecimento de fronteira produzido nas universidades (ARBIX, 2006).

De outra parte, o número de IES não representa uma forte influência da educação superior no desenvolvimento do país. Quando se observa o indicador de 
produtividade do brasileiro, em 1980, a produtividade média era de $35 \%$ da produtividade do norte-americano; em 2002, caiu para 24\%, enquanto alguns países do leste asiático desenvolveram aprendizado tecnológico, criando condições para aumentar o nível de desenvolvimento. Não é só a interação no planejamento entre a economia e o setor da educação superior que alavanca o progresso, é necessário aprimorar os marcos regulatórios e os mecanismos de certificação, é preciso estimular a articulação entre institutos de pesquisa e empresas (ARBIX, 2006).

Pode-se observar no ensino superior brasileiro um crescimento da formação de capital humano qualificado, e a produção de artigos científicos (ver Gráfico 3) apresentou um forte crescimento em publicações indexadas.

Gráfico 3 - Crescimento do número de artigos científicos publicados

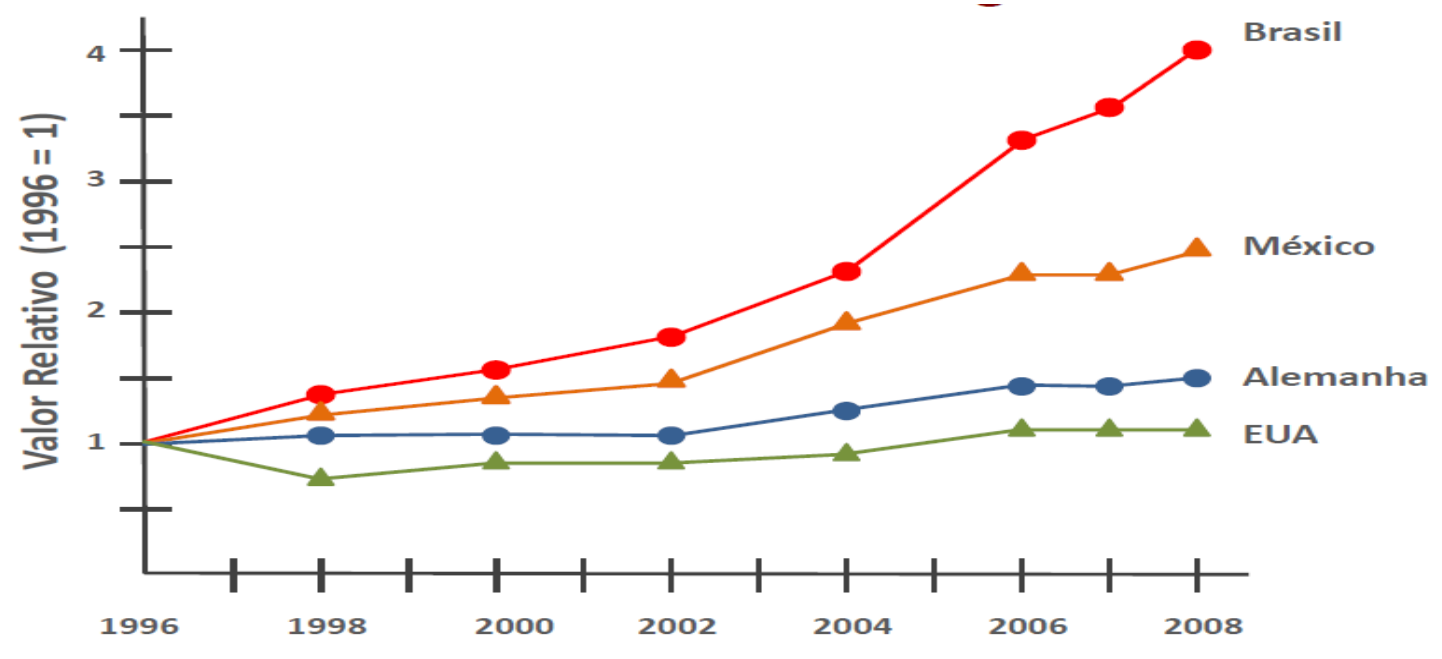

Fonte: Fapesp, 2011.

A expansão deve-se à atuação das IES que oferecem mais vagas e melhor qualificação, sendo ainda um desafio o fortalecimento da relação universidades e empresas. Afinal, a distribuição da oferta de vagas no ensino superior ainda tem baixa participação das áreas tecnológicas, como se observa na Tabela 1, e a relação ingresso/egresso ainda suscita muitas dúvidas com relação à possibilidade de a educação superior alavancar o desenvolvimento. No Gráfico 4, observa-se o aumento da oferta de vagas no ensino superior. 
Tabela 1 - Percentual de matrículas e concluintes, segundo as áreas gerais do conhecimento dos cursos de graduação (presencial e a distância) a que estão vinculados

$$
\text { - Brasil - } 2011
$$

\begin{tabular}{|c|c|c|}
\hline Area Geral do Conhecimento & Matrioulas & Conduintes \\
\hline Géndas Sociais, Negócios e Direito & $41,6 \%$ & $42,3 \%$ \\
\hline Eđucąão & $20,2 \%$ & $23,5 \%$ \\
\hline Saude e Bem-Estar Social & $13,9 \%$ & 14,96 \\
\hline Engenharia, Produçäo e Construção & $11,3 \%$ & $6,4 \%$ \\
\hline Gèncias, Matemática e Computaça & 6,38 & $5,5 \%$ \\
\hline Agricultura e Veterinária & $2,3 \%$ & $2,0 \%$ \\
\hline Humanidades e Artes & $2,3 \%$ & $2,6 \%$ \\
\hline Serviços & $2,1 \%$ & $2,9 \%$ \\
\hline
\end{tabular}

Nota: não inclui área básica de ingresso.

Fonte: MEC/Inep.

Como se observa, não há uma muita discrepância entre o percentual de ingressantes e de concluintes nas várias áreas do conhecimento, destacando ainda que 61,8\% dos ingressantes se concentram nas áreas de ciências sociais e educação e apenas $38,2 \%$ nas demais áreas que concentram maior tecnologia.

Gráfico 4 - Oferta de vagas no ensino superior

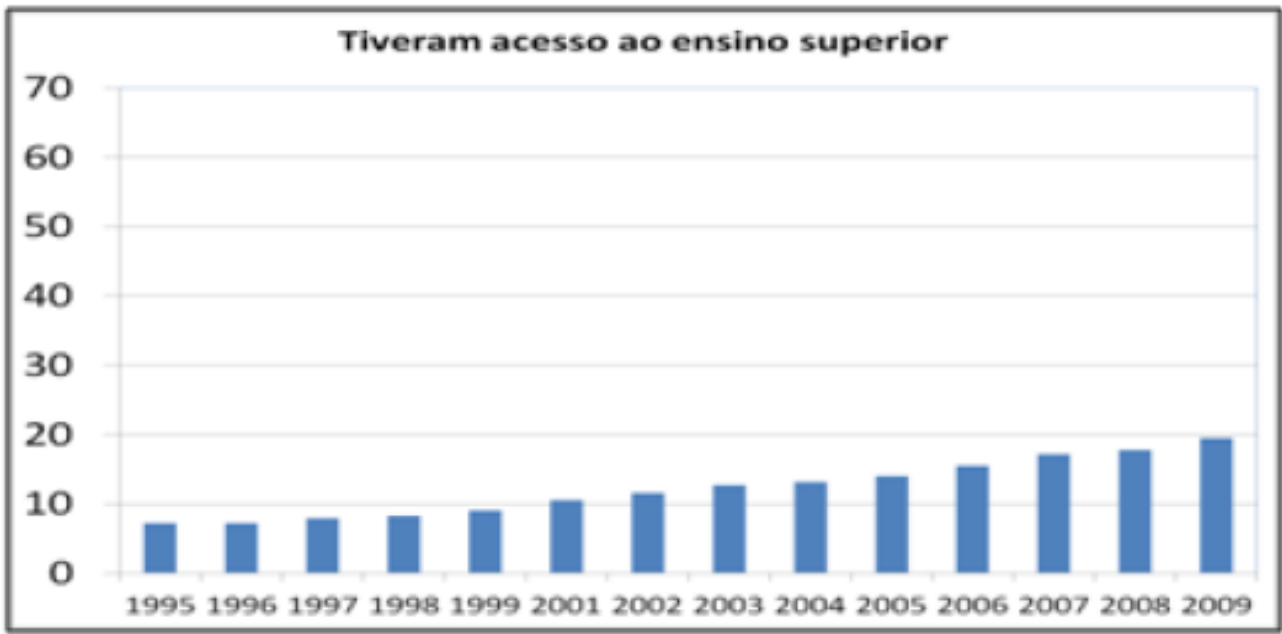

Fonte: IBGE, 2009.

Outra questão estratégica, o número de egressos ainda é muito baixo para atender a demanda do mercado em desenvolvimento, apenas $15,08 \%$ concluem o ensino superior nas duas modalidades de ensino oferecida (ver a Tabela 2). 
Tabela 2 - Número e percentual de matrículas, ingressos (todas as formas e por processo seletivo) e concluintes de graduação, segundo a modalidade de ensino, e respectivos totais absolutos para a graduação presencial - Brasil e regiões geográficas 2011

\begin{tabular}{|c|c|c|c|c|c|}
\hline \multirow{2}{*}{$\begin{array}{l}\text { Modalidade de Envinol } \\
\text { Regiöes Geogrificas }\end{array}$} & \multirow[b]{2}{*}{ Matriculas } & \multicolumn{3}{|c|}{ Ingesses } & \multirow[b]{2}{*}{ Conduintes } \\
\hline & & Total & $\begin{array}{l}\text { por Frocesso } \\
\text { Seletivo }\end{array}$ & Outres Formus & \\
\hline Total & 6.739 .689 & 2.346 .695 & 2093.368 & 253.327 & 1016.713 \\
\hline Total (96) & 100,0 & 100,0 & 100,0 & 100,0 & 100,0 \\
\hline Presencial (\$) & 85,3 & 81,6 & 80,6 & 90,1 & 85,1 \\
\hline a Distinda (\%) & 14,7 & 18,4 & 19,4 & 9,9 & 14,9 \\
\hline
\end{tabular}

Fonte: MEC/Inep.

A Tabela 3, a seguir, mostra outro aspecto importante do ensino superior, a proporção de alunos vinculados ao ensino superior por categoria administrativa

Tabela 3 - Número e percentual de matrículas, ingressos (todas as formas e por processo seletivo) e concluintes de graduação (presenciais e a distância), segundo a categoria administrativa - Brasil - 2010-2011

\begin{tabular}{|c|c|c|c|c|c|c|c|c|c|c|c|}
\hline \multirow{3}{*}{100} & \multirow{3}{*}{ Kregond } & \multirow{2}{*}{\multicolumn{2}{|c|}{ Netichs }} & \multicolumn{6}{|c|}{ lyass } & \multirow{2}{*}{\multicolumn{2}{|c|}{ coditiss }} \\
\hline & & & & \multicolumn{2}{|c|}{ ibl } & \multicolumn{2}{|c|}{ Prancoss Stetion } & \multicolumn{2}{|c|}{ Ctansfonx } & & \\
\hline & & int & 8 & itit & y & $i t \mid$ & $y$ & itit & y & iti & 8 \\
\hline \multirow{6}{*}{ an } & ita & (3)M & 10 & 210218 & 1000 & 19224 & ines & 25950 & 100 & 97839 & 1000 \\
\hline & Alla & 16938 & 88 & $658 \%$ & 2us & 4322 & $B, 1$ & $329 ?$ & DSS & $x=59$ & 96 \\
\hline & forded & 9855 & 14] & 32359 & B.9 & 29MI & 146 & 2254 & 87 & 9955 & 103 \\
\hline & Statel & QuIII & 94 & 14.413 & 6.5 & B55.48 & 18 & 599 & 23 & 2550 & 1,4 \\
\hline & Nosical & 10350 & 16 & 2.112 & is & 20013 & is & 404 & 16 & 1812 & 19 \\
\hline & Find & 478001 & 742 & 17635 & 182. & 1,78848 & 79 & 207397 & 87,5 & 73218 & 8,4 \\
\hline \multirow{6}{*}{ 2i1 } & ldd & 6793960 & 100 & 23665 & 1000 & 209338 & mo & 25330 & 100 & 106573 & 100 \\
\hline & Pata & 1773315 & $x_{3}$ & 4060 & 20 & 57552 & 119 & 33.128 & 13,1 & 21035 & 215 \\
\hline & fithed & $10329 \% 6$ & 153 & 3854 & B., 1 & 2595 & B.) & 22519 & 89 & 111.157 & 109 \\
\hline & Esoded & 619354 & 92 & 105049 & 62 & $13 m$ & 67 & 6177 & 24 & Dox & 86 \\
\hline & Nasiopd & 121.08 & 18 & xald & 15 & $316 \%$ & is & 403 & 11 & 1932 & 19 \\
\hline & Hisd & 4066334 & 73) & 1856015 & $D_{3}, 1$ & 1655916 & 881 & 201919 & 899 & $7 \times 348$ & 785 \\
\hline
\end{tabular}

Percebe-se que as instituições públicas têm uma pequena participação, apenas $25,8 \%$ dos alunos matriculados, o que compromete a qualidade do capital humano, pois 
é do conhecimento geral a melhor qualidade do ensino nessas instituições. A maior participação do ensino privado é agravada pela falta de interação universidade-mercado, provocando uma inflação de egressos em algumas áreas profisssionais. O que afeta a posição brasileira no ranking da produção científica mundial e, consequentemente, na contribuição desse capital no desenvolvimento do país (ver Gráfico 6).

Gráfico 6 - Ranking da produção de artigos científicos

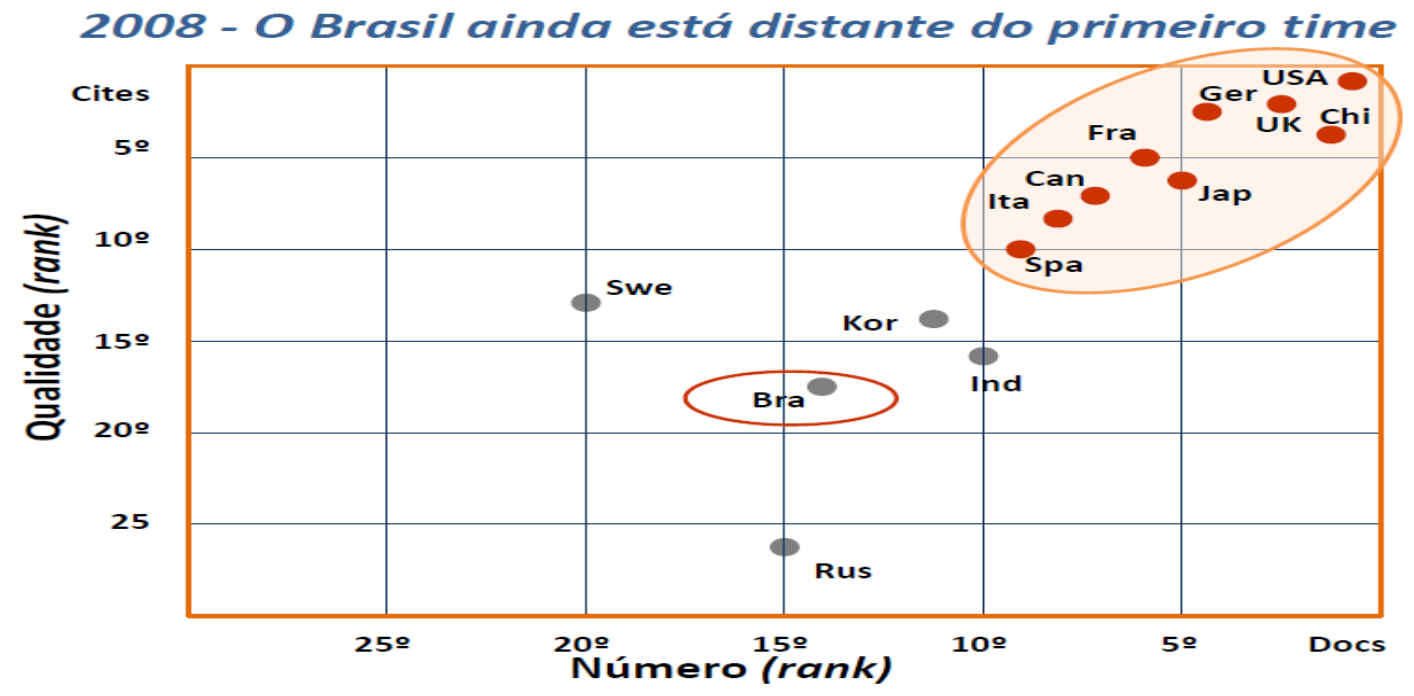

Fonte: Fapesp, 2011.

Os resultados da produção científica no Brasil, embora não tenham uma colocação significativa no ranking mundial, apresentaram um crescimento e contribuíram com o setor econômico, principalmente no setor de maior valor agregado, mostrando a importância do nível educacional superior para impulsionar o crescimento econômico e o desenvolvimento.

No entanto, convém analisar o Gráfico 7 para observar como se encontra a participação na produção científica no nível latino-americano e mundial. 
Gráfico 7 - Publicações brasileiras em revistas científicas catalogadas pela ISI e participação percentual do Brasil na América Latina e no mundo

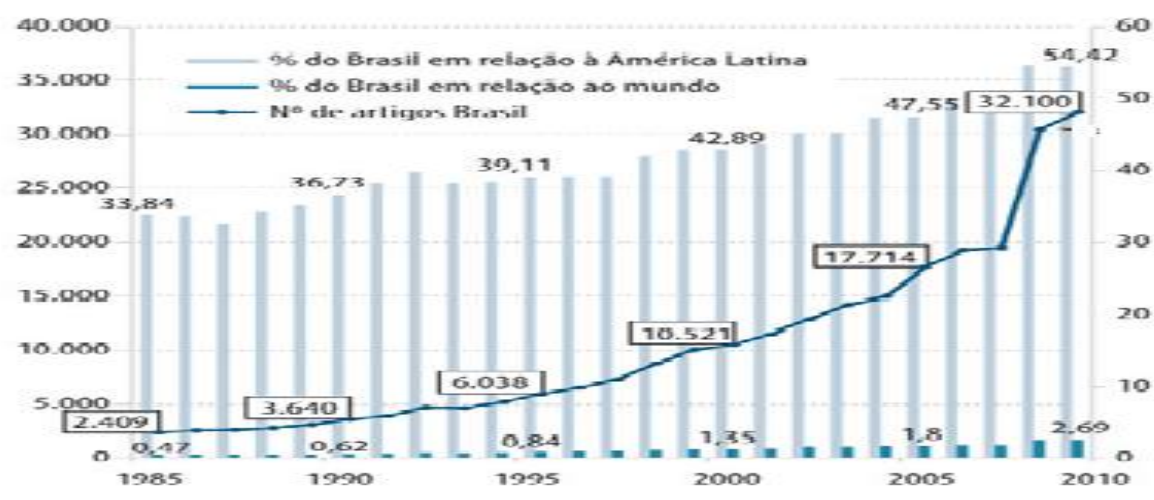

Fonte: apresentação de Glaucius Oliva, presidente do Conselho Nacional de Desenvolvimento Científico e Tecnológico (CNPq) no seminário Caminhos para a Inovação.

Nota-se que existe um longo caminho para que o ensino superior no Brasil possa contribuir de forma efetiva para melhorar as condições socioeconômicas da população, uma vez que o percentual da produção científica é muito baixo no nível mundial.

A trajetória da educação superior no Brasil apresentou crescimento da sua contribuição na produção de conhecimento, contudo ainda se observa que o crescimento não alçou o país no grupo dos países centrais. A posição brasileira pode estar comprometida pela distorção de as categorias apresentarem assimetrias na qualidade do ensino. Outras variáveis, como a ausência de políticas eficazes, de regulação e incentivos para as instituições de ensino, podem dificultar o aumento da qualificação do capital humano. Quanto maior for a qualificação dos egressos do ensino superior, maior será a reversão em produção científica relevante e maior o aproveitamento do capital humano pelo mercado, com possibilidade de executar um desenvolvimento consistente do país.

\section{Considerações finais}

Apesar de a trajetória do ensino superior brasileiro apresentar uma forte assimetria entre setor privado e público e carecer de uma ação qualitativa homogeneizante, para suprir a defasagem histórica que apresenta observamos uma tendência de mudança organizacional para melhorar o panorama do nível de ensino, em 
virtude da influência de modelos estrangeiros ou da própria percepção nacional da importância desse nível da educação nacional para implementar o desenvolvimento.

Observou-se um esforço na melhoria da qualificação do capital humano preparado pelo ensino superior através da produção científica, o que pode representar uma perspectiva nova para um melhor aproveitamento dos quadros formados pelas universidades.

No entanto, ainda é pequena a influência no desenvolvimento do país da educação superior. A interação educação superior-empresa atesta em outros países a pujança econômica e, nesse sentido, uma política nacional de desenvolvimento não pode prescindir dessa interação. No entanto, isso exige uma regulamentação e investimentos no ensino superior que não se pode mais retardar, sob pena de o país apenas apresentar crescimento econômico e não desenvolver em todos os sentidos, como Schumpeter (1961) definiu essas duas dimensões do quadro econômico de uma país.

Espera-se que o planejamento econômico do país integre o ensino superior de forma ampla e não apenas setorialmente, como se observou com a política industrial. É preciso um comprometimento de todos os setores do ensino superior com a qualidade para se alcançar objetivos transformadores da sociedade brasileira. $\mathrm{O}$ desenvolvimento só será alcançado quando todos os entes envolvidos forem contemplados pelo planejamento brasileiro.

Por outro lado, é do senso comum a compreensão de que as mudanças na área educacional não seguem o mesmo ritmo da evolução social. As instituições de nível superior recebem ainda muitas críticas, por se considerar que os egressos não estão adequadamente preparados tendo em vista que a academia se distancia da realidade social.

Enquanto locus propício à reflexão e produção do conhecimento, sob o método científico, não seria esperado que a instituição universitária estivesse a reboque da sociedade, especialmente quando está cada dia mais subordinada à lógica do lucro.

Além de gerar conhecimentos, caberia ao ensino superior brasileiro formar profissionais críticos e capacitados a atuar como agentes dessa transformação, o que demandará uma reformulação dos padrões de formação dos egressos, a começar pela 
inclusão de um núcleo comum de conteúdos que seriam compartilhados por todas as áreas de formação.

\section{REFERÊNCIAS}

ARBIX, G. Política industrial e a perspectiva de futuro para o Brasil. São Paulo. Caderno da Fespsp, n 2, 2006.

BRASIL, Senado Federal. Produção científica no Brasil: um salto no número de publicações. Revista de Audiências Públicas do Senado Federal, ano 3, n 12, 2012.

CARNEIRO, M. A. LDB Fácil: leitura crítico-compreensiva: artigo a artigo. 8. ed. atual. Petrópolis: Vozes, 1998.

CEPAL. Desenvolvimento econômico e educação: perspectivas. In: PEREIRA, L. (Org.). Desenvolvimento, trabalho e educação. Rio de Janeiro: Zahar, 1974.

ECHEVERRÌA, J. M. Funções da educação no desenvolvimento. In: PEREIRA, L. (Org.). Desenvolvimento, trabalho e educação. Rio de Janeiro: Zahar, 1974.

FÁVERO, M. L. A. A universidade no Brasil: das origens à Reforma Universitária de 1968. Educar em Revista, n. 28, 2006.

FRANCO, M. C. A ressignificação da formação profissional superior no contexto da globalização. Revista de La Facultad de Economia - BUAP, v. 6, n. 16, p. 95-106, 2001.

MACHADO, Evelcy Monteiro. Organização do ensino superior no brasil: influências determinantes. 2007. Disponível em: <http://www.utp.br/cadernos_de_pesquisa/pdfs/cad_pesq4/12_organizacao_cp4.pdf>. Data do acesso: 23/01/2014.

MELO, A. L.; SANTOS, E. J. R.; ANDRADE, G. P. Ensino Superior no Brasil: do elitismo colonial ao autoritarismo militar. In: VIII Seminário Nacional de Estudos e Pesquisas "História, Sociedade e Educação no Brasil". História, Educação e Transformação: tendências e perspectivas. 2009. Disponível em: http://www.histedbr.fae.unicamp.br/acer_histedbr/seminario/seminario8/trabalhos.html. Data de acesso: 19 jan. 2014. 
NAGAMINI, M. 1808-1889: ciência e técnica na trilha da liberdade. In: MOTOYAMA, S. (Org.). Prelúdio para uma história: ciência e tecnologia no Brasil. São Paulo: EDUSP; FAPESP, 2004.

PAULA, M. F. A formação universitária no Brasil: concepções e influências. Avaliação, vol. 14, n. 1, p. 71-84, 2009.

PEREIRA, L. C. B. Estratégia nacional e desenvolvimento. Caderno da Fespsp, n. 2, 2006.

SANTOS, L. S.; FREITAS, U. R. P. Pensando a educação superior e o desenvolvimento da Bahia à luz da teoria de crescimento endógeno. Revista Desenbahia, n. 12, 2010. Disponível em: <http://www.desenbahia.ba.gov.br/uploads/2508201114583437_Cap3.pdf>. Acesso em: $1^{\circ}$ mar. 2014.

SCHUMPETER, J. A. The development economics. Oxford. Oxoford University press, 1961.

SCHULTZ, T. W. O valor econômico da educação. Rio de Janeiro: Zahar, 1967. O capital humano. Rio de Janeiro: Zahar, 1973. p. 11-52.

Recebimento dos originais: 04/03/2014

Aceitação para publicação: 01/08/2014 